\title{
Ecological factors related to the widespread distribution of sylvatic Rhodnius ecuadoriensis populations in southern Ecuador
}

Mario J Grijalva ${ }^{1,2^{*}}$, Victoria Suarez-Davalos ${ }^{2}$, Anita G Villacis ${ }^{2}$, Sofia Ocaña-Mayorga ${ }^{2}$ and Olivier Dangles ${ }^{3}$

\begin{abstract}
Background: Chagas disease transmission risk is a function of the presence of triatomines in domestic habitats. Rhodnius ecuadoriensis is one of the main vectors implicated in transmission of Trypanosoma cruzi in Ecuador. This triatomine species is present in domestic, peridomestic and sylvatic habitats in the country. To determine the distribution of sylvatic populations of $R$. ecuadoriensis and the factors related to this distribution, triatomine searches were conducted between 2005 and 2009 in southern Ecuador.

Methods: Manual triatomine searches were conducted by skilled bug collectors in 23 communities. Sylvatic searched sites were selected by a) directed sampling, where microhabitats were selected by the searchers and b) random sampling, where sampling points where randomly generated. Domiciliary triatomine searches were conducted using the one man-hour method. Natural trypanosome infection was determined by microscopic examination and PCR. Generalized linear models were used to test the effect of environmental factors on the presence of sylvatic triatomines.
\end{abstract}

Results: In total, 1,923 sylvatic individuals were collected representing a sampling effort of 751 man-hours. Collected sylvatic triatomines were associated with mammal and bird nests. The 1,219 sampled nests presented an infestation index of $11.9 \%$, a crowding of 13 bugs per infested nest, and a colonization of $80 \%$ of the nests. Triatomine abundance was significantly higher in squirrel (Sciurus stramineus) nests located above five meters from ground level and close to the houses. In addition, 8.5\% of the 820 examined houses in the same localities were infested with triatomines. There was a significant correlation between $R$. ecuadoriensis infestation rates found in sylvatic and synanthropic environments within communities $(p=0.012$ ). Parasitological analysis revealed that $64.7 \%$ and $15.7 \%$ of the sylvatic bugs examined $(n=300)$ were infected with Trypanosoma cruzi and T. rangeli respectively, and $8 \%$ of the bugs presented mixed infections.

Conclusions: The wide distribution of sylvatic $R$. ecuadoriensis populations may jeopardize the effectiveness of control campaigns conducted to eliminate domestic populations of this species. Also, the high T. cruzi infection rates found in sylvatic $R$. ecuadoriensis populations in southern Ecuador could constitute a risk for house reinfestation and persistent long-term Chagas disease transmission in the region.

Keywords: Rhodnius ecuadoriensis, sylvatic triatomines, Ecuador, Chagas disease

\footnotetext{
* Correspondence: grijalva@ohio.edu

${ }^{1}$ Tropical Disease Institute, Department of Biomedical Sciences, Heritage

College of Osteopathic Medicine, Ohio University, Athens OH USA

Full list of author information is available at the end of the article
}

(C) 2012 Grijalva et al; licensee BioMed Central Ltd. This is an Open Access article distributed under the terms of the Creative Commons 


\section{Background}

Chagas disease is caused by the hemoflagellate protozoan parasite Trypanosoma cruzi and is transmitted mainly by the feces of infected triatomine bugs and by blood transfusions [1]. At present, there are 140 extant species formally recognized in the Triatominae subfamily [2]. While all of these are probably capable of transmitting $T$. cruzi, relatively few species show epidemiological importance as vectors of $T$. cruzi to humans [2]. However, most species maintain enzootic cycles involving wild mammals in a variety of biotopes $[3,4]$. Control of the disease has mostly relied on eliminating domestic vector populations [3]; however, the reinfestation of insecticide-treated households by wild vectors is common [5]. Furthermore, sylvatic populations actively transmit the disease in wide regions of the Americas [6,7]. The control of re-infestation of households by wild vectors may therefore be unattainable unless sustained and frequent practices combining several vector control approaches are applied. Traditional approaches that involve spraying households with residual insecticides are unlikely to be effective against triatomines living in sylvatic habitats [3,8,9]. Increasing reports of sylvatic triatomine species invading and sometimes colonizing peridomestic and domestic habitats justifies research on their original wild populations and habitats $[5,9,10]$.

In Ecuador, sixteen triatomine species have been reported [11], and it is believed that at least 13 are vectors or potential vectors of Chagas disease $[11,12]$. Rhodnius ecuadoriensis is an important vector in Ecuador $[9,13,14]$. Studies related to its ecology, feeding, and defecation patterns indicate that this species has bionomic traits of an efficient T. cruzi vector [14]. R. ecuadoriensis is bivoltine and colonizes domestic, peridomestic, and sylvatic habitats. The domestic populations of $R$. ecuadoriensis, considered to be native to western Ecuador, extend from coastal and southern Ecuador to northern Perú $[11,13,15]$. Along the central coastal region of Ecuador and in the subtropical valleys of Santo Domingo de los Tsáchilas Province, its sylvatic habitat has been associated with the endemic palm Phytelephas aequatorialis [11] and other plant species [16]. This species has been found in association with various vertebrate hosts, including squirrels [Sciurus stramineus (Rodentia: Sciuridae)], birds [Campylorhynchus fasciatus (Passeriformes: Troglodytidae)], opossums [Didelphis marsupialis (Didelphimorphia; Didelphidae], and mice [Mus musculus (Rodentia: Muridae)] [9,16-18]. In southern Ecuador, $R$. ecuadoriensis was believed to be located exclusively in domestic areas [11,13], where palm trees are absent, making vector control by means of house spraying feasible. However, the recent report of sylvatic
R. ecuadoriensis associated with squirrel nests (S. stramineus) in southern Ecuador [18] illustrates the need of a new approach for controlling $R$. ecuadoriensis in this region.

The present study aimed to 1) describe the distribution of sylvatic $R$. ecuadoriensis populations in southern Ecuador, 2) identify some ecological factors associated with their abundance in sylvatic habitats, 3) determine their rate of infection with trypanosomes, and 4) discuss the implication of these findings for long-term Chagas disease control efforts in the region.

\section{Methods}

\section{Study area}

From 2005 to 2009 searches of sylvatic triatomines were conducted in 23 communities located in eight counties in Loja Province (Figure 1, Table 1). The sampled microhabitats ranged from 640 to 1,958 m.a.s. 1. and included four vegetation zones (deciduous forest, semi-deciduous forest, green low mountain forest and dry mountain bush forest) [19]. This province has a dry, temperate climate, and the vegetation is dominated by bushes and prickly and herbaceous plants [19]. The main agricultural crops of the region are corn, kidney beans, yucca, papaya, peanuts, bananas, and coffee. The temperature and relative humidity in the sylvatic sites sampled were determined by using LogTag Recorders (Trix-8, Hong Kong, China). Five of these recorders were set for one day to record temperature and relative humidity every hour in selected microhabitats.

\section{Triatomine sampling}

Manual searches for triatomines were conducted in sylvatic habitats in the 23 communities (Table 1 ) by skilled bug collectors. These searches resulted in an effort of 751 man-hours. Microhabitats within these sites-such as animal nests, burrows, tree holes and the ground beneath sticks-were selected and examined once by the searcher. Searched sites were selected by a) directed sampling, where microhabitats were selected by the searchers and b) random sampling, where sampling points where randomly generated.

\section{Directed sampling}

This sampling method was used in 13 communities and allowed searchers to sample areas where it was difficult to locate quadrats or transects, such as river banks and areas between mountains and ravines as previously described [18].

\section{Random sampling}

Manual searches were performed in randomly generated sampling points inside $600 \mathrm{~m}^{2}$-quadrats located in ten communities, as previously described [16]. The sites 


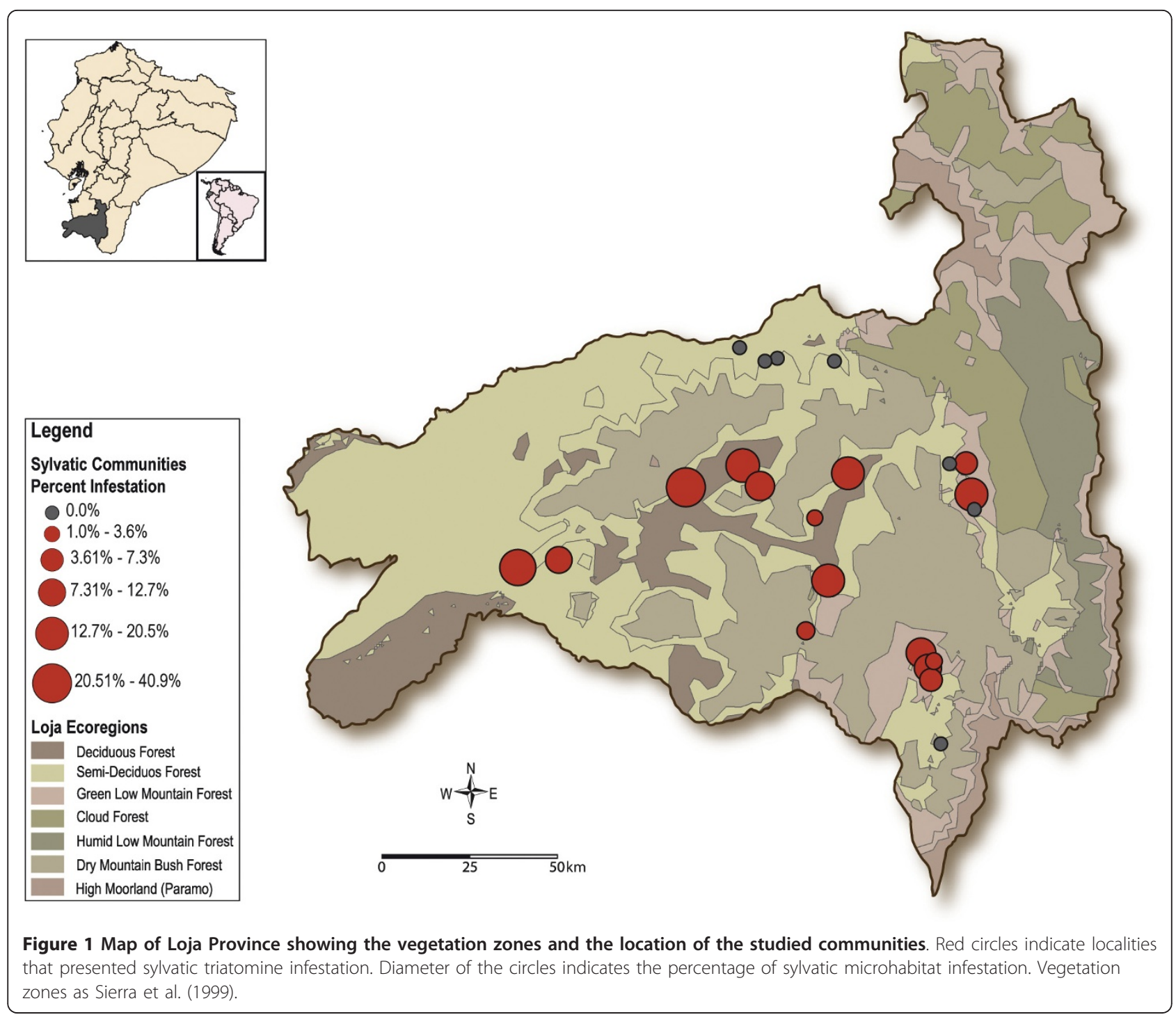

were selected for the high prevalence of triatomineinfested homes and the presence of vegetation patches in the vicinity of houses.

\section{Domicile/Peridomicile searches}

All households in each community were visited. Informed consent was obtained from the head of the household according to a protocol approved by Ohio University and Catholic University of Ecuador Institutional Review Boards. Manual triatomine searches were conducted using the one man-hour method as previously described [13].

Triatomines found in each microhabitat were collected in individually labeled plastic containers and taken to the Insectary at the Center for Infectious Diseases Research, Catholic University of Ecuador, Quito, Ecuador. The specimens were then counted, classified by instar, and identified to species based on morphological criteria $[12,20]$ and by comparisons to specimens stored at the Entomology Museum of the Catholic University (QCAZ) in Quito, Ecuador.

\section{Entomological indexes}

The indexes were calculated for each community sampled and for different microhabitat types found in domiciles and sylvatic areas. The indexes calculated included infestation index $(100 \times$ number of nests or domiciles infested/ number of nests or domiciles examined), density (number of triatomines collected/number of nests or domiciles examined), crowding (number of triatomines collected/ number of nests or domiciles infested) and colonization index (100 × number of nests or domiciles with nymphs/ number of nests or domiciles infested) $[1,16]$.

\section{Generalized linear models (GLMs)}

We used GLMs with a log link to test the effect of environmental factors (type of nest, height from ground 
Table 1 Entomological indices of $R$. ecuadoriensis collected in domestic/peridomestic and sylvatic habitats from 23 rural communities located in Loja province, Ecuador

\begin{tabular}{|c|c|c|c|c|c|c|c|c|c|}
\hline \multirow[b]{2}{*}{ County } & \multirow[b]{2}{*}{ Community } & \multicolumn{4}{|c|}{ Domicile/peridomicile } & \multicolumn{4}{|c|}{ Sylvatic } \\
\hline & & $\begin{array}{l}\text { Infestation } \\
\text { index \% (n) }\end{array}$ & Density & Crowding & $\begin{array}{l}\text { Colonization } \\
\text { index }(\%)\end{array}$ & $\begin{array}{l}\text { Infestation } \\
\text { index \% (n) }\end{array}$ & Density & Crowding & $\begin{array}{c}\text { Colonization } \\
\text { index (\%) }\end{array}$ \\
\hline \multirow[t]{2}{*}{ Calvas } & Chaquizhca & $32.3(31)$ & 1.2 & 3.7 & 40 & $20.5(73)$ & 1.3 & 6.5 & 60 \\
\hline & Jacapo & $0(53)$ & - & - & - & $1.8(56)$ & 0.02 & 1 & 100 \\
\hline \multirow[t]{2}{*}{ Catamayo } & La Extensa ${ }^{a}$ & $4.3(47)$ & 8.2 & 193.5 & 100 & $7.3(41)$ & 0.1 & 1 & 100 \\
\hline & Santa Rita & $0(20)$ & - & - & - & $0(22)$ & - & - & - \\
\hline \multirow[t]{2}{*}{ Celica } & El Guineo $^{a}$ & $0(17)$ & - & - & - & $12.5(48)$ & 1.1 & 87 & 83 \\
\hline & La Ciénega ${ }^{a}$ & $21.4(42)$ & 12.4 & 58 & 78 & $17.4(144)$ & 2.7 & 15.6 & 72 \\
\hline \multirow[t]{5}{*}{ Chaguarpamba } & Amarillos $^{a}$ & $0(39)$ & - & - & - & $0(37)$ & - & - & - \\
\hline & Jorupe & $0(26)$ & - & - & - & $0(24)$ & - & - & - \\
\hline & Lozumbe & $0(25)$ & - & - & - & $0(35)$ & - & - & - \\
\hline & Mizquillana & $0(29)$ & - & - & - & $0(10)$ & - & - & - \\
\hline & Venecia & $0(21)$ & - & - & - & $0(43)$ & - & - & - \\
\hline Espíndola & Tundurama & $1.6(61)$ & 0.02 & 1 & 0 & $0(8)$ & - & - & - \\
\hline \multirow[t]{2}{*}{ Gonzanamá } & Algarrobera & $0(27)$ & - & - & - & $0(9)$ & - & - & - \\
\hline & San Jacinto ${ }^{a}$ & $9.1(11)$ & 6.4 & 70 & 100 & $17.4(190)$ & 3.5 & 20.4 & 82 \\
\hline \multirow[t]{5}{*}{ Paltas } & Ashimingo & $17.2(29)$ & 8.4 & 48.6 & 80 & $20(5)$ & 2.2 & 11 & 100 \\
\hline & Bramaderos $^{a}$ & $19.7(61)$ & 12.4 & 62.9 & 100 & $40.9(66)$ & 4.1 & 10.1 & 85 \\
\hline & Coamine $^{a}$ & $10.9(46)$ & 28 & 257.4 & 80 & $1.5(67)$ & 0.1 & 6 & 100 \\
\hline & Las Cochas & $0(76)$ & - & - & - & $17.4(23)$ & 0.9 & 5.3 & 75 \\
\hline & $\begin{array}{l}\text { Naranjo } \\
\text { Dulce }^{\mathrm{a}}\end{array}$ & $10.8(37)$ & 0.6 & 5.8 & 75 & $12.7(71)$ & 1 & 8.1 & 89 \\
\hline \multirow[t]{4}{*}{ Quilanga } & Galápagos $^{\mathrm{a}}$ & $29.4(34)$ & 21.6 & 73.3 & 100 & $12(117)$ & 1.3 & 10.71 & 86 \\
\hline & Jacapo $Q^{a}$ & $0(22)$ & - & - & - & $3.5(85)$ & 1.7 & 47.3 & 75 \\
\hline & Santa Rosa & $15.4(39)$ & 5.2 & 33.7 & 100 & $5.6(36)$ & 0.6 & 11 & 100 \\
\hline & Tuburo & $18.5(27)$ & 33.5 & 181 & 100 & $11.1(9)$ & 1 & - & 100 \\
\hline Total & & $8.5(820)$ & 6.3 & 73.8 & 83 & $11.9(1,219)$ & 1.6 & 13.3 & 80 \\
\hline
\end{tabular}

${ }^{a}$ communities where random sampling was conducted

level, and distance to the nearest house) and the different combinations of these factors on the number of triatomines found in each random sampling point of the 10 sites where $600 \mathrm{~m}^{2}$ quadrats were sampled. The nonrandom samples were not included in this analysis due to the bias introduced by the searcher during the directed sampling. We used the value of Akaike's Information Criterion (AIC) [21] to study the effect of removing each of the selected ecological factors from the model. Likelihood ratio tests (LRT) were used to test whether the suppression of each factor significantly affects the fit of the model. These analyses were performed using the mass library for $\mathrm{R}[22]$.

\section{Correlation between sylvatic and domestic triatomine infestation}

Spearman's rank correlation coefficient (rho) was used to study the correlation between triatomine infestation in domiciles and triatomine infestation in sylvatic habitats observed in a locality.

\section{Natural Trypanosome infection}

A total of 300 sylvatic triatomines (nymphs III, IV, V and adults) was selected randomly for parasitological analysis. Triatomines were washed in White's solution $(\mathrm{HgCl} 0.8 \mathrm{mM}, \mathrm{NaCl} 111 \mathrm{mM}, \mathrm{HCl} 0.125 \%$, and 25\% $\mathrm{v} / \mathrm{v}$ of ethanol $95 \%$ ) before being dissected under a stereomicroscope. Feces and intestinal content were mixed with $200 \mu \mathrm{l}$ of sterile PBS. One aliquot was used for microscopic examination to detect flagellates and a second aliquot was stored at $-20^{\circ} \mathrm{C}$ for DNA extraction. DNA was extracted with a DNeasy kit (Qiagen, Valencia, CA) following manufacturer's protocol. The presence of trypanosomatid DNA was determined by PCR amplification using the S35/S36 primer set [23]. Stock strain $T$. cruzi and $T$. rangeli DNA were used as positive controls and distilled water was used as negative control in each PCR run. The infection index $(100 \times$ number of infected individuals/total number of analyzed individuals) was calculated for each type of microhabitat. 


\section{Results}

\section{Sylvatic triatomines}

In total, 1,923 $R$. ecuadoriensis specimens were collected in sylvatic habitats from 15 out of 23 localities sampled in Loja Province (Figure 1). The specimens collected belonged to all nymphal stages and adults, with more individuals at the NI and NIII stages (Figure 2). Sylvatic $R$. ecuadoriensis populations were found at altitudes ranging from 661 to 1,663 meters above sea level (m.a.s.l.) and comprising the four sampled vegetation zones (deciduous forest, semi-deciduous forest, green low mountain forest, and dry mountain bush forest). Microhabitat temperature ranged from $15.1^{\circ} \mathrm{C}$ to $31.7^{\circ} \mathrm{C}$ (average of $21.4^{\circ} \mathrm{C}$ ) and the relative humidity from $32.8 \%$ to $100 \%$ (average of $86.2 \%$ ).

\section{Domestic triatomines}

In domiciliary habitats, a total of 5,165 R. ecuadoriensis was collected in 12 of the 23 sampled localities (Table 1). In addition, domiciles were found infested with Triatoma carrioni, Panstrongylus chinai, and P. rufotuberculatus (data not shown). However, we found no sylvatic populations of these three species.

\section{Entomological Indexes}

$R$. ecuadoriensis specimens were found in $11.9 \%$ of the 1,219 sylvatic nests and in $8.5 \%$ of the 820 domiciles that were examined. The overall triatomine density was 1.6 bugs per nest and 6.3 insects per domicile examined (Table 1 ). Triatomine crowding was 13.3 bugs per infested nest and 73.8 bugs per infested domicile. Finally, R. ecuadoriensis nymphs were collected in $80 \%$ of the infested nests and $83 \%$ of the domiciles.

\section{Microhabitats of sylvatic triatomines}

Random searches within quadrats revealed that squirrel nests (S. stramineus) had the highest infestation index $(21.1 \%, \mathrm{n}=71)$, followed by mouse/rat nests $(9.4 \%, \mathrm{n}=$ 74) and bird nests (Campylorhynchus fasciatus 1.4\%, n = 148) (Table 2). No triatomines were found in opossum $(\mathrm{n}=2)$ and armadillo $(\mathrm{n}=25)$ burrows, under rocks ( $\mathrm{n}$ = 32), dead tree trunks ( $\mathrm{n}=118)$, or between leaves and roots of plants [Musa paradisiaca $(\mathrm{n}=67)$, Zea mays ( $\mathrm{n}$ $=7)$, and orchid $(\mathrm{n}=2)$ and bromelia $(\mathrm{n}=1)$ species]. Directed sampling showed triatomine infestation in $22.9 \%$ mouse/rat nests $(n=131)$, followed by a $19.9 \%$ triatomine infestation in squirrel nests $(\mathrm{n}=276), 12.5 \%$ in opossum nests $(\mathrm{n}=8)$ and $3.3 \%$ in bird nests $(\mathrm{n}=$ 390). No triatomines were found in armadillo $(n=7)$ or skunk $(\mathrm{n}=2)$ burrows sampled.

\section{Factors influencing triatomine abundance}

Generalized linear model (GLM) analysis performed on data from the random searches revealed that the factors affecting the abundance of triatomines in sampled microhabitats included type of nest, nest's height from ground level, nest's distance to nearest house, and the combination type of nest $\times$ height from ground level (Table 3, Figure 3). While all these factors significantly explained observed variations in triatomine abundance $(\mathrm{P}<0.001)$, removing the "type of nest" factor from the overall GLM model caused the highest increase in AIC. This suggests that nest type is one of the main drivers of triatomine abundance in sylvatic habitats.

Additionally, there was a significant correlation between the triatomine infestation index found in domiciliary units and in sylvatic habitats within the same locality (Spearman's rho $=0.507, p=0.012$ ).

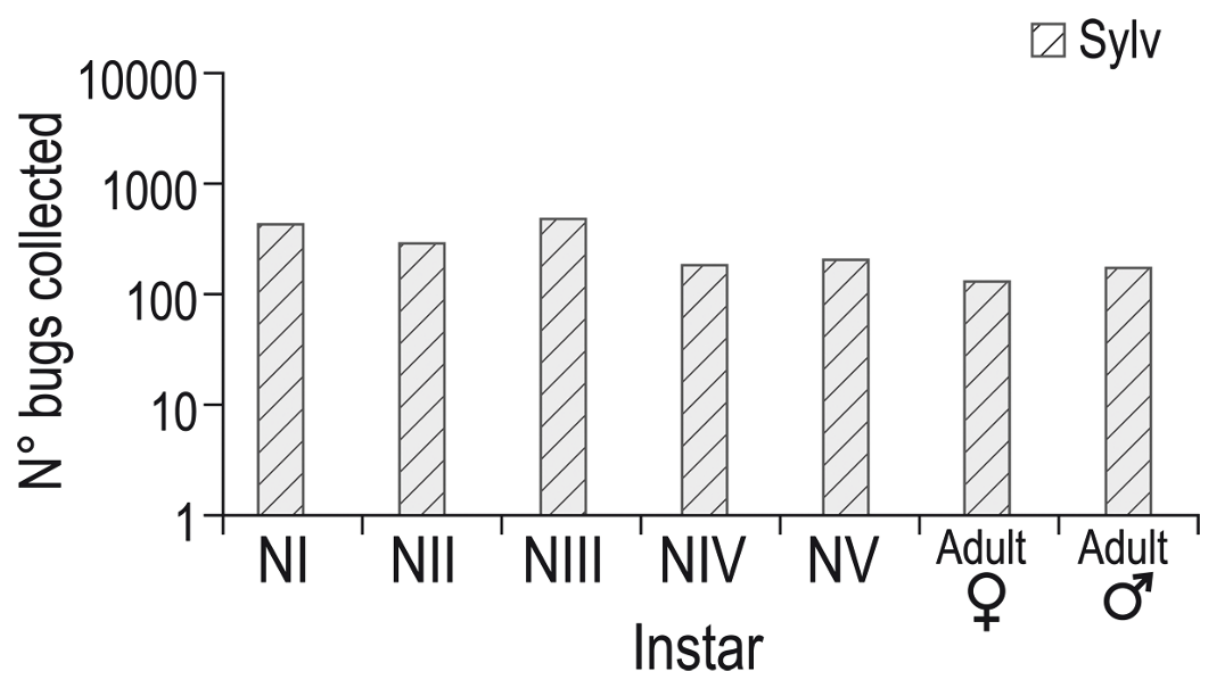

Figure 2 Population structure of triatomines collected in sylvatic habitats of 15 localities of Loja province. 
Table 2 Infestation index by nest types found random searches in quadrats sampled in 10 rural communities located in Loja Province, Ecuador

\begin{tabular}{|c|c|c|c|c|c|c|c|c|c|}
\hline \multirow{3}{*}{ Community } & \multicolumn{9}{|c|}{ Type nest } \\
\hline & \multicolumn{3}{|c|}{ Squirrel } & \multicolumn{3}{|c|}{ Mouse/rat } & \multicolumn{3}{|c|}{ Bird } \\
\hline & $\begin{array}{c}\text { No. } \\
\text { examined }\end{array}$ & $\begin{array}{c}\text { No. } \\
\text { infested }\end{array}$ & $\begin{array}{c}\text { Infestation } \\
\text { index } \\
(\%)\end{array}$ & $\begin{array}{c}\text { No. } \\
\text { examined }\end{array}$ & $\begin{array}{c}\text { No. } \\
\text { infested }\end{array}$ & $\begin{array}{c}\text { Infestation } \\
\text { index } \\
(\%) \\
\end{array}$ & $\begin{array}{c}\text { No. } \\
\text { examined }\end{array}$ & $\begin{array}{c}\text { No. } \\
\text { infested }\end{array}$ & $\begin{array}{c}\text { Infestation } \\
\text { index } \\
(\%)\end{array}$ \\
\hline Amarillos & 12 & - & - & 7 & - & - & 4 & - & - \\
\hline Bramaderos & 11 & 6 & 54.5 & 4 & 2 & 50 & 3 & - & - \\
\hline Coamine & - & - & - & 4 & - & - & 18 & - & - \\
\hline El Guineo & 5 & 2 & 40 & 5 & - & - & 5 & - & - \\
\hline Galápagos & 4 & - & - & 8 & 3 & 37.5 & 11 & - & - \\
\hline Jacapo Q & 6 & - & - & 15 & 1 & 6.7 & 8 & - & - \\
\hline La Ciénega & 17 & 4 & 23.5 & 2 & - & - & 22 & - & - \\
\hline La Extensa & - & - & - & 4 & - & - & 13 & 1 & 7.7 \\
\hline $\begin{array}{l}\text { Naranjo } \\
\text { Dulce }\end{array}$ & 16 & 3 & 18.8 & 16 & 1 & 6.2 & 19 & 1 & 5.3 \\
\hline San Jacinto & - & - & - & 7 & - & - & 44 & - & - \\
\hline Total & 71 & 15 & 21.1 & 74 & 7 & 9.4 & 148 & 2 & 1.4 \\
\hline
\end{tabular}

Natural Trypanosoma infection in sylvatic $R$. ecuadoriensis A total of 300 triatomines collected in different sylvatic habitats from 13 communities in 6 counties was analyzed parasitologically (Table 4). PCR showed that $72.3 \%$ of the sylvatic $R$. ecuadoriensis were infected with trypanosomatids. Of these, $56.7 \%$ and $7.7 \%$ presented single infection with $T$. cruzi and T. rangeli, respectively, and $8 \%$ presented mixed infections with $T$. cruzi and T. rangeli (Table 4). The parasite T. cruzi was found in 10 out of 13 communities and in at least one community in each county indicating widespread distribution of infected $R$. ecuadoriensis in sylvatic habitats. Triatomines collected in squirrel nest microhabitat presented the highest $T$. cruzi infection index $(73.4 \%, \mathrm{n}=177$ bugs), followed by rat/mice nests $(53.6 \%, \mathrm{n}=112$ ) (Table 4). Although triatomines collected in bird nests accounted only for $3.7 \%$ of the total analyzed bugs, infection with T. cruzi was found $36.4 \%$ of them (2 NIII and 2 adult males out of 13 analyzed individuals). Conversely, $T$. rangeli was found in bugs collected in rat/ mouse nests (19.6\%) and squirrel nests (14.1\%). No $T$.

Table 3 Results of the Generalized Linear Model's analysis on triatomine samplings

\begin{tabular}{ccccc}
\hline Effect & Terms included in the model & AIC & $\Delta$ AIC & $\mathbf{P}$ \\
\hline all & all & 1315 & & $<0.001$ \\
nest*height & all & 1315.8 & $0.8<0.001$ \\
height & all & 1320.1 & 5.1 & $<0.001$ \\
distance & all & 1375.4 & 60.4 & $<0.001$ \\
nest & all & 1388.3 & 73.3 & $<0.001$ \\
\hline
\end{tabular}

Akaike's Information Criterion (AIC) is given to test for the significance of selected ecological factors on triatomine infestation. The factors or combination of factors that presented change in AIC value are listed rangeli infected bugs were collected in bird nests (Table 4). Natural infection with $T$. cruzi was found to be higher in adults than in nymphs and appears to increase with developmental stage. Conversely, $T$. rangeli infection was higher in nymphs than in adults (Table 5).

\section{Discussion}

$R$. ecuadoriensis is widely distributed in southern and western Ecuador and north-western Peru and is considered an important T. cruzi vector. The presence of sylvatic triatomine populations of this species [18] may pose a problem to Chagas disease control efforts in domestic environments, especially when these populations have marked synanthropic tendencies and could potentially re-infest domestic habitats after spraying campaigns from sylvatic environments [13].

\section{Sylvatic population of $R$. ecuadoriensis in southern Ecuador}

Our results showed 1) a wide distribution of sylvatic populations of $R$. ecuadoriensis throughout Loja Province and 2) a considerable infestation of rodent nests, which are highly abundant in the region. In the studied communities, the sylvatic distribution and abundance of this species seems to follow closely household infestation. Earlier reports indicated that $R$. ecuadoriensis was restricted to domestic and peridomestic habitats in Loja Province and northern Peru $[11,24,25]$. If so, spraying homes with insecticide could have been an effective control strategy. Moreover, previous reports from Peru suggested that $R$. ecuadoriensis had no sylvatic ecotypes, its presence being more related to passive transportation with humans [24,25]. In Ecuador, a pilot project 


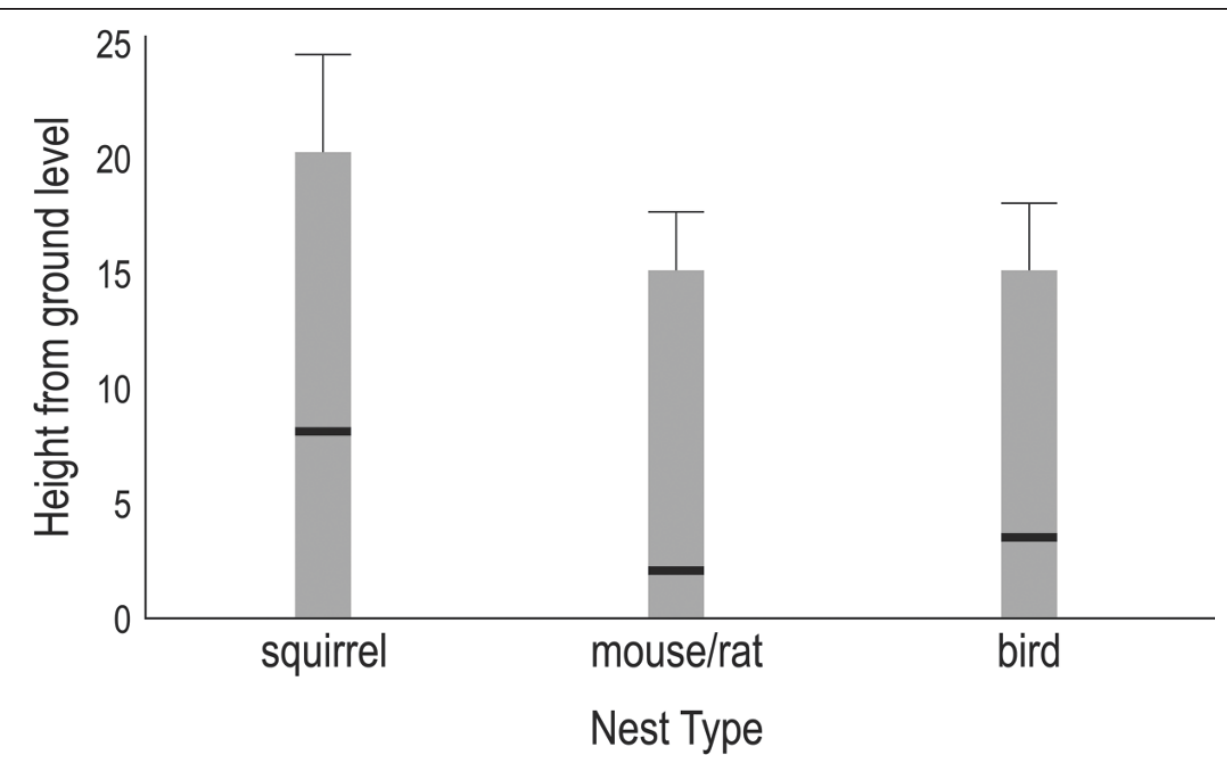

Figure 3 Heights from ground level of tree types of nests sampled in 10 sylvatic quadrats located in Loja province. Black line shows the mean height and error bars show the standard deviation.

Table 4 Natural trypanosomatid infection ${ }^{a}$ in sylvatic $R$. ecuadoriensis collected in 13 localities from Loja province, Ecuador

\begin{tabular}{|c|c|c|c|c|c|}
\hline County & Comunity & Microhabitat $(n)^{b}$ & $\%$ T. cruzi & $\%$ T. rangeli & Mixed infections \\
\hline \multirow[t]{3}{*}{ Calvas } & Chaquizhca & Squirrel nest (15) & 80.0 & 6.7 & - \\
\hline & & Rat/mouse nest (6) & - & - & - \\
\hline & & Bird nest (2) & 50.0 & - & - \\
\hline Catamayo & La Extensa & Bird nest (2) & 50.0 & - & - \\
\hline \multirow[t]{3}{*}{ Celica } & La Ciénega & Squirrel nest (11) & 72.7 & - & - \\
\hline & & Rat/mouse nest (4) & - & - & - \\
\hline & El Guineo & Squirrel nest (17) & 35.3 & 11.8 & - \\
\hline \multirow[t]{3}{*}{ Gonzanamá } & San Jacinto & Squirrel nest (38) & 78.9 & - & 7.9 \\
\hline & & Rat/mouse nest (55) & 63.6 & 9.1 & 12.7 \\
\hline & & Bird nest (2) & 50.0 & - & - \\
\hline \multirow[t]{6}{*}{ Paltas } & Ashimingo & Rat nest (1) & - & - & - \\
\hline & Bramaderos & Squirrel nest (57) & 61.4 & 8.8 & 15.8 \\
\hline & & Rat/mouse nest (27) & 40.7 & 29.6 & 7.4 \\
\hline & Coamine & Squirrel nest (6) & 100.0 & - & - \\
\hline & Las Cochas & Squirrel nest (2) & 50.0 & - & - \\
\hline & Naranjo Dulce & Squirrel nest (6) & 16.7 & - & - \\
\hline \multirow[t]{5}{*}{ Quilanga } & Galápagos & Squirrel nest (17) & 58.8 & 11.8 & 11.8 \\
\hline & & Rat/mouse nest (19) & 26.3 & - & - \\
\hline & & Bird nest (5) & 20.0 & - & - \\
\hline & Jacapo Q & Squirrel nest (7) & 85.7 & - & 14.3 \\
\hline & Tuburo & Squirrel nest (1) & - & - & - \\
\hline \multirow[t]{3}{*}{ All communities } & & Rat/mouse nest & 45.5 & 11.6 & 8.0 \\
\hline & & Squirrel nest & 65.0 & 5.6 & 8.5 \\
\hline & & Bird nest & 36.4 & 7.7 & - \\
\hline TOTAL & & All microhabitats (300) & 56.7 & 7.7 & 8 \\
\hline
\end{tabular}

a Determined by PCR analysis.

${ }^{\mathrm{b}}$ Number of triatomines analyzed from each type of microhabitat 
Table 5 Natural $T$. cruzi and $T$. rangeli infection ${ }^{a}$ in relationship to the population structure of 300 sylvatic $R$. ecuadoriensis collected in 13 localities from Loja province, Ecuador

\begin{tabular}{ccccc}
\hline $\begin{array}{c}\text { Triatomine } \\
\text { Instar }\end{array}$ & $\mathbf{n}$ & $\begin{array}{c}\text { T. cruzi } \\
\text { only } \\
\%\end{array}$ & $\begin{array}{c}\text { T. rangeli } \\
\text { only } \\
\%\end{array}$ & $\begin{array}{c}\text { T. cruzi \&T. rangeli } \\
\text { mixed } \\
\%\end{array}$ \\
\hline Male & 83 & 67.5 & 4.8 & 7.2 \\
Female & 76 & 69.7 & 0.0 & 9.2 \\
N V & 53 & 50.9 & 11.3 & 17.0 \\
N IV & 40 & 42.5 & 17.5 & 2.5 \\
N III & 48 & 35.4 & 12.5 & 2.1 \\
\hline Total & 300 & 56.7 & 7.7 & 8.0 \\
\hline a Determined by PCR analysis. & &
\end{tabular}

including spraying efforts in 25 communities in the Loja province showed a reduction in triatomine infestation in domicile and peridomicile habitats (Grijalva et al. unpublished data). However, some communities with high household infestation presented continuous reinfestation after spraying. The high number of $R$. ecuadoriensis collected in sylvatic habitats located close to the dwellings could be the source of this re-infestation in domicile and peridomicile habitats. However, detailed studies of patterns and sources of re-infestation are still needed to determine the importance of sylvatic $R$. ecuadoriensis populations in Chagas disease transmission in Ecuador.

Additionally, the distribution of sylvatic R. ecuadoriensis closely depends on ecological associations. Sylvatic populations of species from the pallescens complex, which includes $R$. pallescens, $R$. colombiensis, and $R$. ecuadoriensis, have been found in wild habitats associated with palm trees. The first two species were particularly associated with Attalea butyracea [12,20,26,27] while $R$. ecuadoriensis has been associated with Phytelephas palm trees [11]. However, our results indicate that $R$. ecuadoriensis presence appears to be more associated to vertebrate hosts distribution than to any given species of plant [16-18].

\section{Factors influencing triatomine abundance}

Although environmental variables such as altitude, climate, vegetation type, and land use all affect triatomine presence at a small spatial scale [28], these likely do so indirectly, by increasing the availability of suitable habitats for triatomine hosts. From sylvatic habitats, triatomines can spread over long distances through passive dispersal, as eggs, nymphs and adults may be transported in human clothes, mammalian hair or bird feathers $[12,29,30]$.

Our study identified key factors explaining R. ecuadoriensis abundance in sylvatic habitats such as the type of nest, nest height from ground and nest distance to the nearest house. These results agree with previous results performed in the coastal region of Ecuador (Manabí Province) [16]. Squirrel nests are commonly infested with triatomines, probably due to the size and loose construction of the nest, the size of the animal (as a food source), and the animals' constant occupancy of the nest. These nests were found at a height up to 20 meters, but were more commonly at about 8 meters. Such high height seems to be related to ecological preferences of squirrels which generally look for large, tall trees providing more nesting places, a better thermal insulation, and lower risk of predation [31]. The distribution of the squirrel species S. stramineus in Ecuador seems to coincide with that of $R$. ecuadoriensis (from 0 to 2000 m.a.s.l., central and southern coast and occidental Andes slope of Ecuador) [32]. The role of this squirrel species in the dispersal of sylvatic populations of $R$. ecuadoriensis needs to be further explored, as it may have important implications for the long-term control of Chagas disease in Ecuador. Mouse and rat nests were also significantly infested. They were more numerous than squirrel nests, but of smaller size. In southern Ecuador, Rattus rattus has been considered an important reservoir of T. cruzi [33] and implicated as a possible link of sylvatic $T$. cruzi populations in domestic transmission [34]. In addition, field observations indicate that squirrels are highly mobile, attracted by the crops, and frequently abandon nests, which in turn become occupied temporarily or permanently by rats. This behavior of nest re-users could explain the high T. cruzi infection rate found in rats and reinforces the possible role of these mammalian hosts as an important link between sylvatic and domestic transmission cycles. Finally, our results corroborate previous reports of the presence of $R$. ecuadoriensis in nests of the fasciated wren (Troglodytidae: Campylorhynchus fasciatus) whose large and loosely knitted nests provide adequate conditions for this triatomine species [16-18].

Within a given community, we found a significant correlation between triatomines abundance in sylvatic habitats and distance from human dwellings. Locations near homes probably offer more food sources, which may help triatomines to survive in deforested areas. As the distance from triatomine source sites contribute to bug establishment rate [35], there are important implications of knowing triatomine source sites for controlling house re-infestations after spraying. A study on reinfestation processes in Argentina suggests that Chagas disease control program should consider potential sources of triatomines up to $1,500 \mathrm{~m}$ around the dwelling to reduce adult invasion [36].

We also observed higher triatomine infestation rates in areas with water sources and vegetation that provides animal nesting places and food. Deforestation leads to a 
decrease in wild vertebrate populations, which could in turn decrease populations of sylvatic triatomines, but residual populations could feed on opportunistic marsupials and rodents. In addition, starving triatomine adults from large colonies would fly into nearby homes, leading to an increased risk of disease transmission [37].

\section{Infection rates with trypanosomes in $R$. ecuadoriensis}

Our study showed high infection rate of $R$. ecuadoriensis with $T$. cruzi thereby confirming the role of this triatomine as a major vector of the Chagas disease in southern Ecuador $[9,13]$. In addition, the high infection rates observed with $T$. rangeli are also consistent with previous reports $[24,25]$ and could constitute confounding factors in epidemiological studies.

Fifty six samples of $T$. cruzi from sylvatic triatomines collected during this study were genotyped and determined as belonging to the Discrete Typing Unit (DTU) T. cruzi I (TcI) [34]. Microsatellite analyses grouped most samples $(n=53)$ as part of a sylvatic genotype population that appeared genetically separated from a cluster formed by the domestic/peridomestic population. Although limited, genetic flow among sylvatic and domestic/peridomestic trypanosomes was evident. As mentioned before, the complex interactions of vectors and host, especially in sylvatic environments, could play an important role in transmission of the disease in the studied area. To elucidate this scenario, a longitudinal study that compares the original parasite isolates with those isolated from triatomines collected after control intervention needs to be conducted. Also the role of synanthrophic mammals, which could connect both environments, must be clarified.

\section{Interactions between sylvatic and non-sylvatic $R$. ecuadoriensis populations}

Recent morphometric analyses of wings and antennal phenotype indicated that sylvatic and domicile/peridomicile populations of $R$. ecuadoriensis shared phenotypic characteristics in Loja province suggesting a continuous exchange of individuals between both environments [38]. Although triatomine re-infestation found after spraying campaigns in southern Ecuador (Grijalva et al. unpublished data) could be due to the presence of remnant populations of bugs that have not been killed by the insecticide, we hypothesize that the arrival of sylvatic populations to dwellings may be an important re-infestation source.

\section{Conclusions}

Vectorial transmission of Chagas disease relies on the presence of triatomines in domestic habitats. Although conclusive evidence does not yet exists that the postspraying house reinfestation is due to sylvatic bug migration, we propose that the widespread presence of sylvatic populations of $R$. ecuadoriensis could jeopardize long-term control of Chagas disease transmission in southern Ecuador. If this information is corroborated, alternative control measures should be implemented in areas with documented presence of sylvatic $R$. ecuadoriensis populations. Control interventions should include systematic and periodic active and passive entomological surveillance, insecticide spraying, house improvement programs, insecticidal paints [39], community education, and monitoring of sylvatic triatomine populations.

\section{List of Abbreviations}

DTU: Discrete Typing Unit; GLMs: Generalized Linear Models; AIC: Akaike's Information Criterion; LRT: Likelihood ratio tests.

\section{Acknowledgements}

We thank the field entomologists from the National Chagas Control Program, Ecuadorian Ministry of Public Health. This study benefited from the international collaboration of the European Community Latin American Network for Research on the Biology and Control of Triatominae (ECLAT) and the technical advice of Dr. Christopher Schofield. Technical assistance was provided by Cesar Yumiseva, Esteban G. Baus and Alejandra Zurita, collaborators at the Center for Infectious Disease Research, Pontifical Catholic University of Ecuador (PUCE). Financial support was received from UNICEF/ UNDP/World Bank/WHO Special Programe for Research and Training in Tropical Diseases (TDR) Research Capability Strengthening group (grant ID number A20785), the Division of Microbiology and Infectious Diseases, National Institute of Allergy and Infectious Diseases, National Institutes of Health (DMID/NIAID/NIH), Children's Heartlink Minneapolis, Plan International Ecuador, Ohio University College of Osteopathic Medicine, PUCE and the Ecuadorian Ministry of Public Health.

\section{Author details}

${ }^{1}$ Tropical Disease Institute, Department of Biomedical Sciences, Heritage College of Osteopathic Medicine, Ohio University, Athens OH USA. ${ }^{2}$ Center for Infectious Disease Research, Pontifical Catholic University of Ecuador, Quito, Ecuador. ${ }^{3}$ IRD UR072, LEGS UPR 9034, CNRS 91198 Gif-sur Yvette Cedex and Université Paris-Sud 11, France.

\section{Authors' contributions}

MJG: conceived of the study, and participated in its design and coordination, performed data analyses and helped to draft the manuscript. VS-D: contributed to the sampling design, conducted sylvatic triatomine collection, data analysis and drafted the manuscript. AGV: directed entomological collection, triatomine identification, data analyses and helped to draft the manuscript. SO conducted parasitological analyses and helped to draft the manuscript. OD: Conceived the study, contributed to the design and data analyses and helped to draft manuscript. All authors read and approved the final manuscript.

\section{Competing interests}

The authors declare that they have no competing interests.

Received: 13 October 2011 Accepted: 13 January 2012

Published: 13 January 2012

\section{References}

1. WHO: Control of Chagas disease World Health Organization; 2002, 2002/07/ 03 edn.

2. Schofield CJ, Galvao C: Classification, evolution, and species groups within the Triatominae. Acta Trop 2009, 110:88-100.

3. Noireau F, Carbajal-de-la-Fuente AL, Lopes CM, Diotaiuti L: Some considerations about the ecology of Triatominae. An Acad Bras Cienc 2005, 77:431-436. 
4. Schofield CJ, Kabayo JP: Trypanosomiasis vector control in Africa and Latin America. Parasit Vectors 2008, 1:24.

5. Guhl F, Pinto N, Aguilera G: Sylvatic triatominae: a new challenge in vector control transmission. Mem Inst Oswaldo Cruz 2009, 104(Suppl 1):71-75.

6. Miles MA, Feliciangeli MD, de Arias AR: American trypanosomiasis (Chagas' disease) and the role of molecular epidemiology in guiding control strategies. BMJ 2003, 326:1444-1448.

7. Morel CM, Lazdins J: Chagas disease. Nat Rev Microbiol 2003, 1:14-15.

8. Dumonteil E, Ruiz-Pina H, Rodriguez-Felix E, Barrera-Perez M, RamirezSierra MJ, Rabinovich JE, Menu F: Re-infestation of houses by Triatoma dimidiata after intra-domicile insecticide application in the Yucatan peninsula, Mexico. Mem Inst Oswaldo Cruz 2004, 99:253-256.

9. Grijalva MJ, Villacis AG, Ocana-Mayorga S, Yumiseva CA, Baus EG: Limitations of selective deltamethrin application for triatomine control in central coastal Ecuador. Parasit Vectors 2011, 4:20.

10. Schofield CJ, Diotaiuti L, Dujardin JP: The process of domestication in Triatominae. Mem Inst Oswaldo Cruz 1999, 94(Suppl 1):375-378.

11. Abad-Franch F, Paucar A, Carpio C, Cuba CA, Aguilar HM, Miles MA: Biogeography of Triatominae (Hemiptera: Reduviidae) in Ecuador: implications for the design of control strategies. Mem Inst Oswaldo Cruz 2001, 96:611-620.

12. Lent $H$, Wygodzinsky P: Revision of the Triatominae (Hemiptera: Reduviidae), and their significance as vectors of Chagas disease. Bol Am Mus Nat Hist 1979, 163:123-520.

13. Grijalva MJ, Palomeque-Rodriguez FS, Costales JA, Davila S, Arcos-Teran L: High household infestation rates by synanthropic vectors of Chagas disease in southern Ecuador. J Med Entomol 2005, 42:68-74.

14. Villacis AG, Arcos-Teran L, Grijalva MJ: Life cycle, feeding and defecation patterns of Rhodnius ecuadoriensis (Lent \& Leon 1958) (Hemiptera: Reduviidae: Triatominae) under laboratory conditions. Mem Inst Oswaldo Cruz 2008, 103:690-695.

15. Abad-Franch F, Aguilar VH, Paucar CA, Lorosa ES, Noireau F: Observations on the domestic ecology of Rhodnius ecuadoriensis (Triatominae). Mem Inst Oswaldo Cruz 2002, 97:199-202.

16. Suarez-Davalos V, Dangles O, Villacis AG, Grijalva MJ: Microdistribution of sylvatic triatomine populations in central-coastal Ecuador. J Med Entomol 2010, 47:80-88.

17. Grijalva MJ, Palomeque FS, Villacis AG, Black CL, Arcos-Teran L: Absence of domestic triatomine colonies in an area of the coastal region of Ecuador where Chagas disease is endemic. Mem Inst Oswaldo Cruz 2010, 105:677-681.

18. Grijalva MJ, Villacis AG: Presence of Rhodnius ecuadoriensis in sylvatic habitats in the southern highlands (Loja Province) of Ecuador. J Med Entomol 2009, 46:708-711.

19. Sierra R: Propuesta preliminar de un sistema de clasificación de vegetación para el Ecuador Continental Quito: Proyecto INEFAN/BIRF y Ecociencia; 1999.

20. Carcavallo RU, Galíndez-Giron I, Jurberg J, Galvao C, Lent H: Pictorial keys for tribes, genera and species of the subfamily Triatominae. In Atlas of Chagas' Disease Vectors in the Americas. Volume I. Edited by: Carcavallo RU, Galíndez-Giron I, Jurberg J, Lent H. Rio de Janeiro: Editora Fiocruz; 1998:107-244

21. Venables WN, Ripley BD: Modern applied statistics with S-Plus New York, New York, USA 2002.

22. R-Development-Core-Team: $R$ a Language and Environment for Statistical Computing. Foundation for Statistical Computing Vienna, Austria 2009.

23. Vallejo GA, Guhl F, Chiari E, Macedo AM: Species specific detection of Trypanosoma cruzi and Trypanosoma rangeli in vector and mammalian hosts by polymerase chain reaction amplification of kinetoplast minicircle DNA. Acta Trop 1999, 72:203-212.

24. Cuba CA, Abad-Franch F, Roldan Rodriguez J, Vargas Vasquez F, Pollack Velasquez $L$, Miles MA: The triatomines of northern Peru, with emphasis on the ecology and infection by trypanosomes of Rhodnius ecuadoriensis (Triatominae). Mem Inst Oswaldo Cruz 2002, 97:175-183.

25. Vargas F, Cordova Paz Soldan O, Marin C, Jose Rosales M, SanchezGutierrez R, Sanchez-Moreno M: Epidemiology of American trypanosomiasis in northern Peru. Ann Trop Med Parasitol 2007, 101:643-648.

26. Arevalo A, Carranza JC, Guhl F, Clavijo JA, Vallejo GA: [Comparison of the life cycles of Rhodnius colombiensis Moreno, Jurberg \& Galvao, 1999 and
R. prolixus Stal, 1872 (Hemiptera, Reduviidae, Triatominae) under laboratory conditions]. Biomedica 2007, 27(Suppl 1):119-129.

27. Zeledon R, Marin F, Calvo N, Lugo E, Valle S: Distribution and ecological aspects of Rhodnius pallescens in Costa Rica and Nicaragua and their epidemiological implications. Mem Inst Oswaldo Cruz 2006, 101:75-79.

28. Bustamante DM, Monroy MC, Rodas AG, Juarez JA, Malone JB: Environmental determinants of the distribution of Chagas disease vectors in south-eastern Guatemala. Geospat Health 2007, 1:199-211.

29. Abrahan LB, Gorla DE, Catala SS: Dispersal of Triatoma infestans and other Triatominae species in the arid Chaco of Argentina: flying, walking or passive carriage? The importance of walking females. Mem Inst Oswaldo Cruz 2011, 106:232-239.

30. Forattini OP, Rocha e Silva EO, Ferreira OA, Rabello EX, Pattoli DG: [Ecological aspects of trypanosomiasis. 3. Local dispersion of triatominae with special reference to Triatoma sordida]. Rev Saude Publica 1971, 5:193-205.

31. Meyer MD, Kelt DA, North MP: Nest trees of northern flying squirrels in the Sierra Nevada. J Mammal 2005, 86:275-280.

32. Tirira D: Mammals from Ecuador; field guide Quito, Ecuador 2007.

33. Pinto CM, Ocana-Mayorga S, Lascano MS, Grijalva MJ: Infection by trypanosomes in marsupials and rodents associated with human dwellings in Ecuador. J Parasitol 2006, 92:1251-1255.

34. Ocana-Mayorga S, Llewellyn MS, Costales JA, Miles MA, Grijalva MJ: Sex, subdivision, and domestic dispersal of Trypanosoma cruzi lineage I in southern Ecuador. PLoS Negl Trop Dis 2010, 4:e915.

35. Zu Dohna H, Cecere MC, Gurtler RE, Kitron U, Cohen JE: Spatial reestablishment dynamics of local populations of vectors of chagas disease. PLoS Negl Trop Dis 2009, 3:e490.

36. Cecere MC, Vasquez-Prokopec GM, Gurtler RE, Kitron U: Reinfestation sources for Chagas disease vector, Triatoma infestans, Argentina. Emerg Infect Dis 2006, 12:1096-1102.

37. Abad-Franch F, Monteiro FA: Biogeography and evolution of Amazonian triatomines (Heteroptera: Reduviidae): implications for Chagas disease surveillance in humid forest ecoregions. Mem Inst Oswaldo Cruz 2007, 102(Suppl 1):57-70.

38. Villacis A, Grijalva MJ, Catalá SS: Phenotypic variability of Rhodnius ecuadoriensis populations at the Ecuadorian central and southern Andean region. J Med Entomol 2010, 47:1034--1043.

39. Amelotti I, Catala SS, Gorla DE: Experimental evaluation of insecticidal paints against Triatoma infestans (Hemiptera: Reduviidae), under natural climatic conditions. Parasit Vectors 2009, 2:30.

doi:10.1186/1756-3305-5-17

Cite this article as: Grijalva et al:: Ecological factors related to the widespread distribution of sylvatic Rhodnius ecuadoriensis populations in southern Ecuador. Parasites \& Vectors 2012 5:17.

\section{Submit your next manuscript to BioMed Central and take full advantage of:}

- Convenient online submission

- Thorough peer review

- No space constraints or color figure charges

- Immediate publication on acceptance

- Inclusion in PubMed, CAS, Scopus and Google Scholar

- Research which is freely available for redistribution

Submit your manuscript at www.biomedcentral.com/submit
C Biomed Central 